\title{
2D Advertising in 3D Virtual Spaces
}

\section{Borbála Berki}

Széchenyi István University, Multidisciplinary Doctoral School of Engineering

Sciences; Egyetem tér 1, H-9026 Győr, Hungary

berki.borbala@sze.hu

\begin{abstract}
D$ advertising in $V R$ is more effective than in the classic banner ad format, our study confirms that ads in VR evoke better memory, namely more participants remembered the advertisement displayed in VR than the web-based ad. Advertising in virtual realities does not have to mean a virtual space exclusively dedicated to the promoted product. It can be a $2 D$ ad inserted in the virtual space. It differs from the classic web-based ads, as it is not inserted in the content of a webpage, but stands alone in a virtual space. In this paper, we show a comparison of the classic banner ads, and $2 D$ ads placed in a $3 D$ virtual world. The effectiveness of the VR advertisement is higher than the classic web-based ads. In our experiment 22 people were involved. As the virtual space, we used the MaxWhere virtual platform, where the participant's task was to read four online articles. In one condition four banner ads were placed on each webpage, in the other condition, the advertisement was placed in the virtual space. Then, they answered questions about the article and the advertisement.
\end{abstract}

Keywords: virtual reality; MaxWhere; advertisement; internet advertising; marketing

\section{Introduction}

Throughout history advertising has appeared on various platforms to reach wide audience and to obtain attention to the promoted product. From the sales messages written on Egyptian papyrus, through the $19^{\text {th }}$ Century's image with slogan style, advertisements have changed in many different ways, to find the most efficient forms to influence the consumers. Nowadays, the TV ads and online advertising are the focus of the advertising industry. As the interest in virtual realities increases, advertisers tend to focus on this new media to exploit its potentials.

\subsection{Classic Web-based Advertising}

Along with the increase in the number of Internet users around the world, online ads became a more and more important part of the advertising industry. In the first half of 2017, the digital advertising revenues in the United States reached $\$ 40.1$ 
billion, which means a unique $22.6 \%$ growth in one year [1]. Correspondingly, we can find several advertisements in almost every kind of website. For example, when you read an online newspaper you can see banner ads at the top and/or at the bottom of the article or maybe at the sidebar or they use pop-ups in a new window. You can also meet with short commercials wedged in between two videos. Various forms of advertisements appeared along with the growing of the internet, but here is a general definition from Louisa Ha for the online advertising: Deliberate messages placed on third-party websites including search engines and directories available through Internet access [2]. In this paper, we focus on banner ads and do not cover the topics of social media ads.

All form of online advertising spring from print advertising, therefore they have a lot of similarities in terms of arrangement, text and graphic design. However, online advertising pushes the advantages of the digital world and supplements the still pictures with hyperlinks, various animations and sound effects to capture the attention of the consumers. One of the most common formats of online ads is banner ads, where the advertiser pays for space on one or more online pages to display a static or linked banner or logo [1]. These ads are examined in various studies [2] [3] [4] [5]. People have different attitudes to different ad formats, but it seems that consumers attribute the highest information factor to banner ads, and the highest overall positive attitude [4].

The effectiveness of an advertisement also depends on the media credibility and content congruence with the webpage. The online market requires consumers to make decisions about products without commonly used first-hand, physical experiences. Therefore, credibility has a greater role in online marketing than in traditional advertising industry. As advertisements never appear alone, they are embedded in non-advertising content; their reliability is judged on the base of the website and advertiser credibility. Banner ads on credible sites produce a more positive advertising outcome. The content compatibility means that the advertised product matches the website content thus consumers find it more interesting and useful [6]. Yet, this overall positive attitude is not toward the ad itself, but toward the brand and purchase intent [7].

As can be seen, the classic web-based advertisement is a widely examined subject since not only academics but practitioners are also concerned to find the most effective methods. Classic web-based advertisements share some common features, including embeddedness, which can be interpreted as they are always breaking the content, even the related ones. This can be a disadvantage as it can irritate the users and evokes ad avoidance.

Irritation is another contributing factor in advertising effectiveness. It is important to realize that advertisements can evoke a strong resistance from users as they typically try to block or just ignore them. When an individual is attempting to carry out a specific goal, the appearing advertisement is perceived as an aggravation, particularly by those users who understand the online persuasion 
strategies (larger sizes, animations) [8]. Banner ads are generally displayed on the periphery; they do not interrupt directly the activity of web viewers. In contrast, pop-up ads are one of the most irritating web-based advertisement forms. According to the Interactive Advertising Bureau's definition, pop-up ads (or formally interstitials) are advertisements that appear in a separate window which automatically loads over an existing content window [1]. Therefore, users are forced to react to these commercial messages. For this interruption, the individuals can respond cognitively, affectively or behaviorally, which can be both positive and negative for the advertiser. A positive effect could be that because of this unexpected interruption, users will have greater processing and increased memory for the pop-up advertisement [6]. On the other hand, interstitials cause a negative attitude formation which can lead to the avoidance of the ads [9].

Why do consumers find only some advertising irritating and not all of them? The answer is the so-called intrusiveness: the interruption of editorial content [9]. This sounds a bit controversial, as the first objective of advertising is to get noticed, to be as salient as possible, thus interruption of editorial content should be a key characteristic of all advertisement. Whereas ads were related to the web user's task, they were perceived less intrusive [9]. The evoked negative attitudes and reactance could result in ad avoidance and feeling of irritation. Reactance theory is a social psychological theory which describes the human behavior as a response to the perceived loss of freedom in an environment. When an individual feels that his opportunities or freedom narrows, the reactance helps to re-establish the control of a situation and a sense of freedom [10]. This reactance is also present in advertising. Consumers actively interpret advertisements and react against the threats of persuasion. As ads are perceived less intrusive when related to the web user's task, the same manner, the more value is perceived in an ad (more information or entertainment) and it is evaluated as less intrusive. On the other hand, keep in mind that most consumers do not see high entertainment or information value of web-based advertisements. [6]. Avoidance is not a necessary consequence of an intrusive advertisement, the degree to which an ad is judged to be intrusive is more important [6]. The degree of this reactance depends on the importance of the threatened behavior, the severity of the threat, whether the threat affects other freedoms and whether the person ever actually enjoyed that freedom [10].

As described previously, advertisers tend to find new ways and new media to deliver their commercial messages to potential consumers. Virtual reality is a fastgrowing field, where advertisers are trying to find more effective ways of advertising. 


\subsection{MaxWhere VR}

The development of operating systems has a huge impact on the effectiveness of using a computer. From DOS, operated by text-based commands to the GUI (Graphical User Interface), like Windows OS, the ease of use evolved remarkably fast. The use of visual metaphors instead of the linguistic commands allowed more intuitive interactions with computers for a wider range of users. Displaying graphics, color pictures, videos became an essential feature; as did the option of multitasking by switching between different windows. The biggest advantage is that cognitive load was reduced during performing a task. The MaxWhere VR environment attempts to make a further step in this process to expand intuitive interactions from two dimensions to 3D. Along with the transformation of operating systems, information pressure is also increasing. To digest this incredible amount of data we can benefit from the possibilities of the 3D visualization, which enable an even more intuitive interaction with any data, even with advertisements. Fundamentally advertisements are visual constructs, but can take advantage of 3D too. For example, a better memory of ads if they are placed in the space or users can create expectations about ads.

A similar change can be observed between $2 \mathrm{D}$ and $3 \mathrm{D}$ browsing. In a classic $2 \mathrm{D}$, browser tabs cover each other, tab organizing is uneasy and all the tab has the same size irrespective of its content. In contrast, browsing in 3D can create a transparent and clear overview of all tabs, users can organize and group the tabs according to their desires. The tabs can have different size; a bigger tab for a calendar with a month view and a narrower for a chat tab. In 3D the tabs do not cover each other (Figure 1).

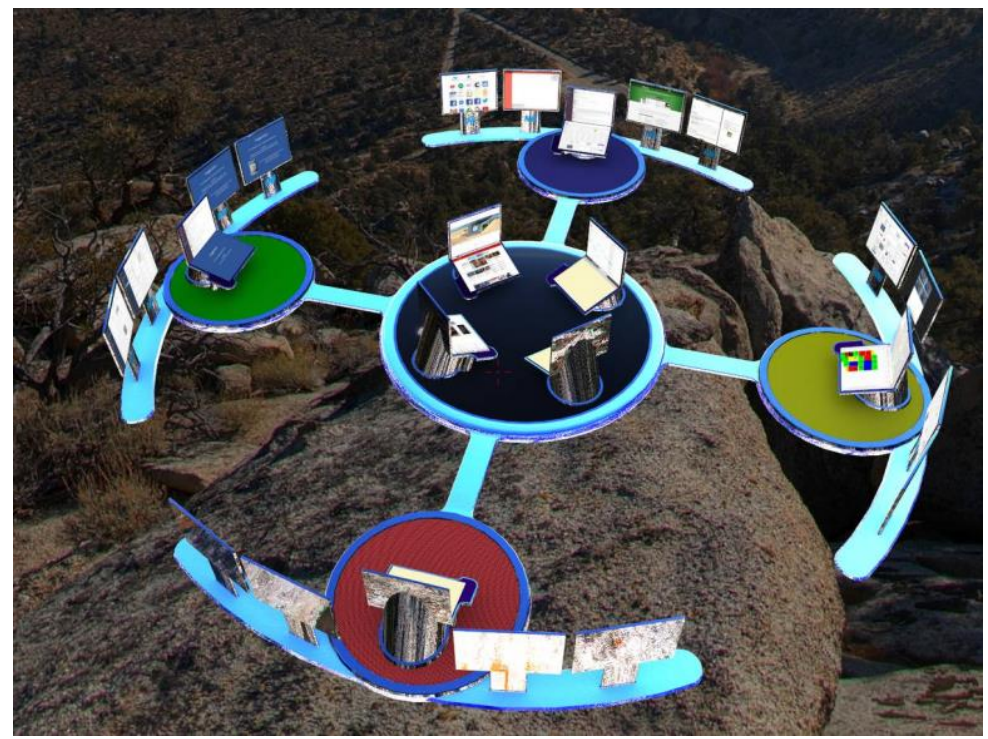

Figure 1

Grouping of webtables in MaxWhere VR 
Advertisements can benefit from a context-based placement [6], which can be implemented more effectively in a 3D environment. In shared virtual spaces they can be more personalized according to the target group. If everyone in the group could be interested, the ad is placed in a big webtable in the central part. If it is interesting for just one individual of the group then it could be displayed on a smaller personal advertisement area.

The most important differences between classic web-based and VR advertisement are that they differ in both modes of delivery and in the target audience. While the web advertisements have more written parts and designed for those who run a content-oriented information search, in a virtual environment, the users are more image and entertainment-oriented [11].

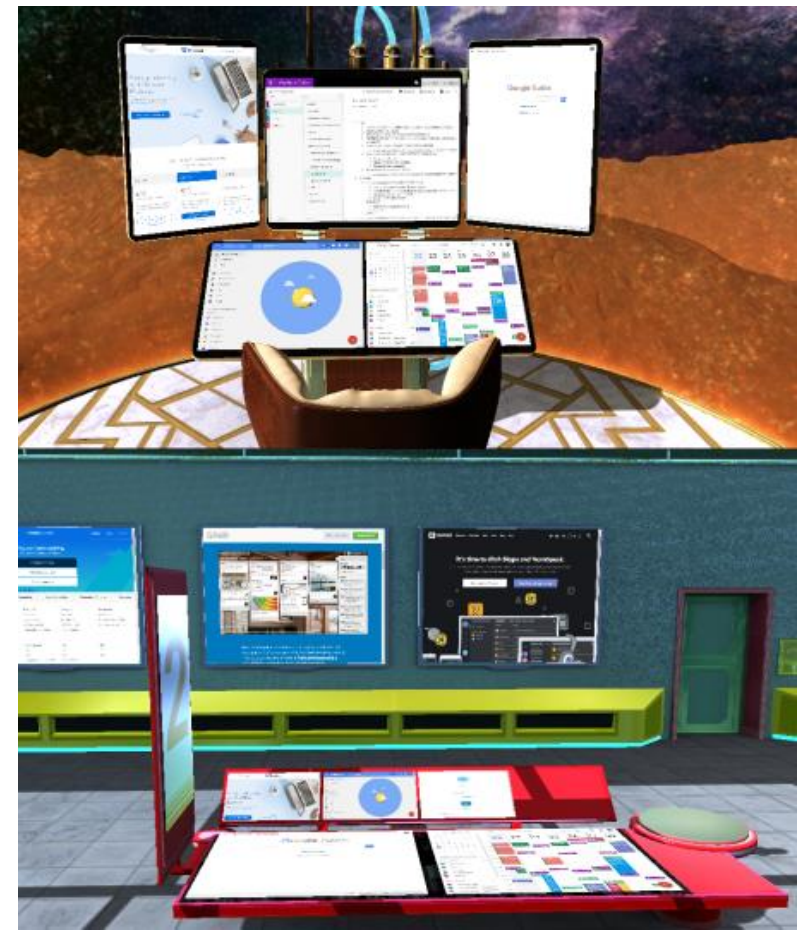

Figure 2

Webtables in different MaxWhere spaces

In our experiment, we used the MaxWhere VR engine. This is an innovative desktop based VR environment that integrates the opportunities provided by web technologies (HTML5, JavaScript, CSS) and 3D graphics with spatial metaphors. MaxWhere was developed by Mistems Ltd., with support in content creation from the Széchenyi István University. A great advantage of this environment is the user-friendly solutions, like the simple navigation in the space with a keyboard, 
and the easy content upload, and management. All content is displayed on webtables, which are mostly landscape format with the widely used 4:3 proportion. On these smarttables, the user can display any web pages, cloud-based applications, real-time communication programs and PDF documents, images, videos and audio files from the PC (Figure 2). The user only writes the address to the address bar of the webtable. In a word, in this VR environment, the Internet literally surrounds the user [12] [13].

In the field of the VR-based education, along with other software, the MaxWhere VR has been used in scientific research [12] [13] [14] [15] [16] [17] [18] [19] [20], and also used for virtual reconstruction of historical buildings [21].

We used the MaxWhere VR in our experiment because it enables to place the advertisements in the space, like in a real world, they stand alone and they are not embedded in content, like in web pages.

\section{Aim of the Study}

The aim of our study was to compare the advertisement effectiveness of $2 \mathrm{D}$ ads in VR and in classic web-based form. We suppose that advertisements placed in a virtual space are more effective than ads placed on websites. As a measure of the effectiveness, we have taken the memory performance of the subjects, more precisely the number of participants who could recall the advertisement. To test our hypothesis we used a between-subject design; namely we divided the participants into two group to test simultaneously the ad effectiveness of advertisements in VR and in the classic web-based form. Our hypothesis was that in the VR group more individuals will remember that they have seen an advertisement than in the other group.

\subsection{Contrast to Other VR Advertising Research}

Advertisers use different methods to evoke the attention of customers. A widespread VR advertising method is to create virtual experiences, where users can get a kind of first-hand information about the product, before the acquisition [26]. As an illustration, we can take destination marketing, as a promotion tool, advertisers try to encourage real-life tourism visits by offering VR experiences. In this field, the visual imagery is essential to focus attention on to a special destination [27]. Another type of VR marketing method is the avatar-based advertising, where an attractive avatar gives information about a product or helps to choose an item in a virtual store. The effectiveness of these different advertisements depends on several factors, for example, the physical attractiveness of a spokes-avatar is a mediating factor [25]. But what are the most important 
success factors in virtual worlds? According to Tikkanen and his colleagues, the value for customers, the community management, and highly interactive applications can be the biggest advantages [26].

Three dimensional is a key feature in virtual realities, which has been already established by advertisers. They realized that in an online shopping environment the 3D images are more persuasive for any customer. There are of course some differences regarding the type of product: in the case of geometric products (e.g.: watch) there is an even greater effect of $3 \mathrm{D}$ than in a case of a material product (e.g.: jacket) [27] [28]. The user's individual characteristics are also an important factor: if a person has a high need for touch, to decide, this user is less impressed by the 3D version of a jacket, than another consumer who does not feel this need to touch a product before purchasing [27]. Another characteristic of the 3D display is that it enhances the sense of presence in a virtual space and influence the product knowledge and purchase intention. This greater sense of presence is irrespective of the type of product (geometric or material) [29]. These examples are part of informational advertising, where the emphasis is on the details and knowing the product.

In contrast, the transformational advertisements are those, in which the emphasis is on the experience of using the product. For example, an advertisement showing a person feeling adventurous and lively when using a product. This type of ad influences the attitude toward the advertisement and the brand. These transformational ads were found more efficient when they were shown in $3 \mathrm{D}$ via a cardboard-type head-mounted device than showed in 2D [29]. In destination marketing, the VR-based advertisement generated more emotions toward the destination and the individuals found it more engaging [23].

The exposure effect is a well-known psychological effect which means that customers misattribute the increase of accessibility of a brand as liking of the brand. In other words, if an individual is exposed to an advertisement or a product, they see it regularly, they are going to interpret this, as they like the product [30]. Another advantage of product placement is that it could enhance the feeling of realism of the virtual space. Correspondingly, there are more ads for real products than for fictitious products in a video game, as this also can increase the sense of presence in this alternative reality [11]. Another advantage of the product placement is that it is less obtrusive. Namely, the media users are less likely to develop the above-mentioned psychological reactance toward the ad [6]. On the contrary, when product placement is compared with billboard placement in virtual realities, the object and brand recall for products advertised on billboards were greater than the product placement [31].

The presence, the feeling of immersion is the individual subjective feeling of being in the displayed virtual world. This presence could be a mediator between the ad format (2D or 3D) and the advertisement effectiveness [27] [32]. This 
presence and high immersion also could evoke the affective engagement of the users [31].

The type of VR device also plays an important role in the effectiveness of an advertisement. A head-mounted device or a CAVE (cavern automatic virtual environment) can create a higher sense of presence as they are a more immersive system than a desktop monitor but this doesn't mean that the advertising is more efficient there. Moreover, better memory recall and more efficient brand advertising result were found in the case of a VR displayed on a desktop monitor. Another interesting remark of this research is that in the immersive system the location of an advertisement was more important than its actual size [33].

To sum up prior researches focused on the effects of the 3D visualization of advertisements [26] [27] [28], or virtual prototypes [11] [31], but rarely focused on the comparison between the classic web-based and VR-based 2D advertisements.

\section{Methods}

\subsection{Subjects}

In our experiment 22 individuals participated (18 male, 4 female; mean age: 23.45 years (SD:2.26)). All subjects had a basic knowledge of the MaxWhere software. Individuals participated voluntarily in the study. The whole experiment was conducted in Hungarian, all participants were native Hungarian speakers. Twelve participants were in the VR group, ten in the classic web-based ad group.

\subsection{MaxWhere Space}

To compare the efficiency of the advertisement in virtual spaces and the advertisements on web pages, we used the MaxWhere VR environment because it enables displaying both web pages and advertisements. The MaxWhere Environment 1.4.x software [34] is developed for visualization of 3D graphical templates and user contents. The 3D graphical templates are integrated parts of the software. All used computers matched the system requirements of the MaxWhere software: MS Windows 7 or newer (system memory: min. $8 \mathrm{~GB}$; min. free storage: $2 \mathrm{~GB}$, min. GPU: Intel HD Graphics 4400 or newer), MacOS System (memory: minimum 8 GB, min. free storage: 2 GB; GPU: Intel Iris graphics 6100 or newer). 
For the experiment, we used the CogInfoCom17 space (artist: G. Kovács; FIEK program at SZIU), which is a special version of the Lecture Space SZIU. This space was designed for lectures, homework, and presentations. We used the central area, the original personal corner, and information desk to display the contents of the experiment.

\subsection{Procedure}

We used a between-subject experimental design to compare the results of the participants of different groups. Individuals were randomly assigned to one of the two conditions (classic web-based or VR advertisement). The web-based advertisement group saw four online articles in the central area of the virtual space. All articles contained a banner ad on the right side of the page. The same advertisement on all four sites (Figure 3). In the two conditions, the total area of advertisements was equaled.

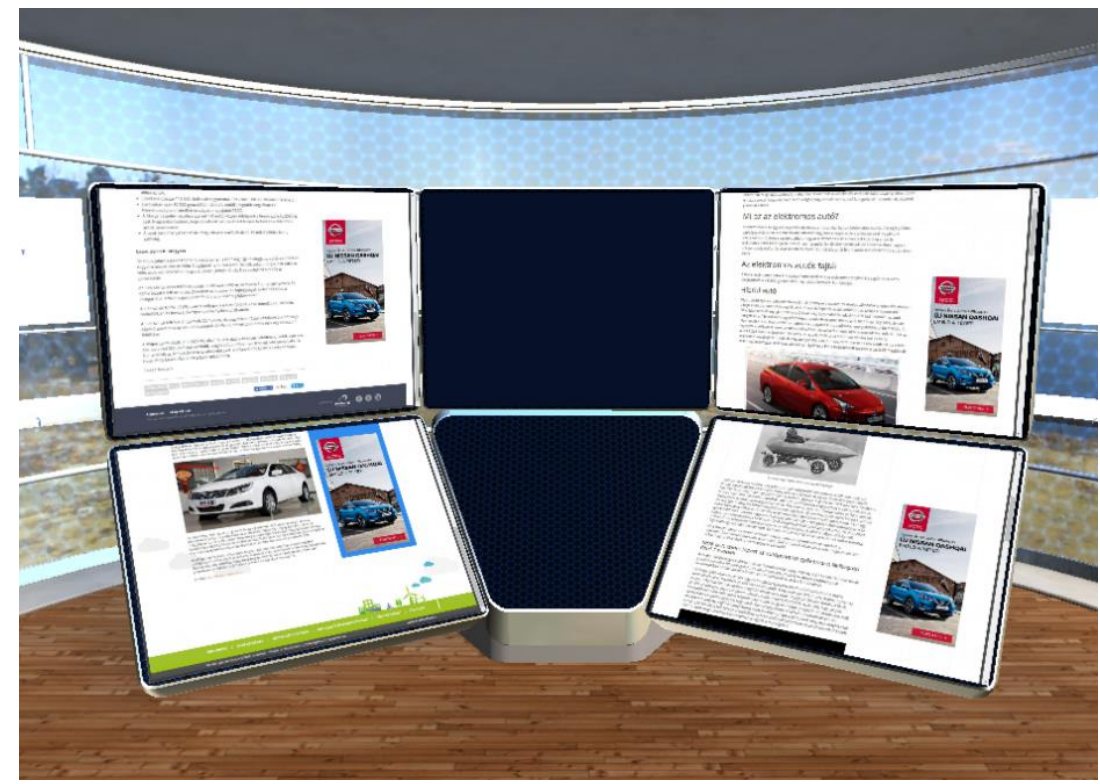

Figure 3

Classic web-based advertisements

The individuals in the VR advertisement group saw the same four articles with the same spatial layout, but without the banner ads. For this group, the advertisement was displayed on a separate webtable, among the four articles (Figure 4). The surface of the advertisements was the same in both conditions. 


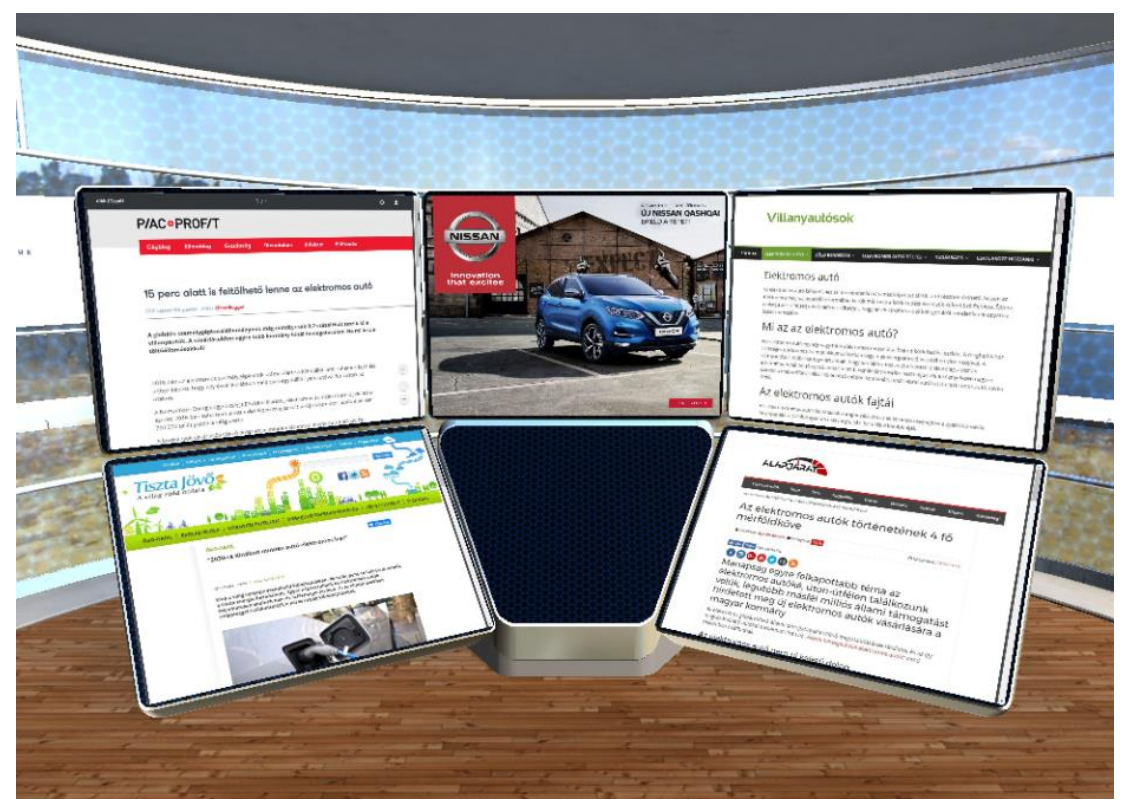

Figure 4

VR based advertisement

During the experiment, the participants filled an online questionnaire, placed in the MaxWhere VR space. This questionnaire was the same for every individual regardless of the experimental group. The questionnaire contained all the instructions to fulfill the experiment. On the first page, they read a short description of the whole task (without any references to the aim of the study) and with a click, they indicated their willingness to participate in the study. Then they had to answer general questions about the four articles displayed on the central area. Then they had to import another pack (pack is an archive file that can be exported from the MaxWhere environment and contains copies of and/or references to User content as well as an optional list of 3D positions and orientations pertaining to the $3 \mathrm{D}$ template [34]). Then all the previous content (except for the questionnaire) were replaced with pictures. For checking whether the participants made this import, the next question was about the picture. Then they were asked if they remember any advertisement in the virtual space. If they answered yes, they were asked to write as many details as they can about the advertisement (brand, product, colors, slogan, etc.) and answered some basic demographical question. 


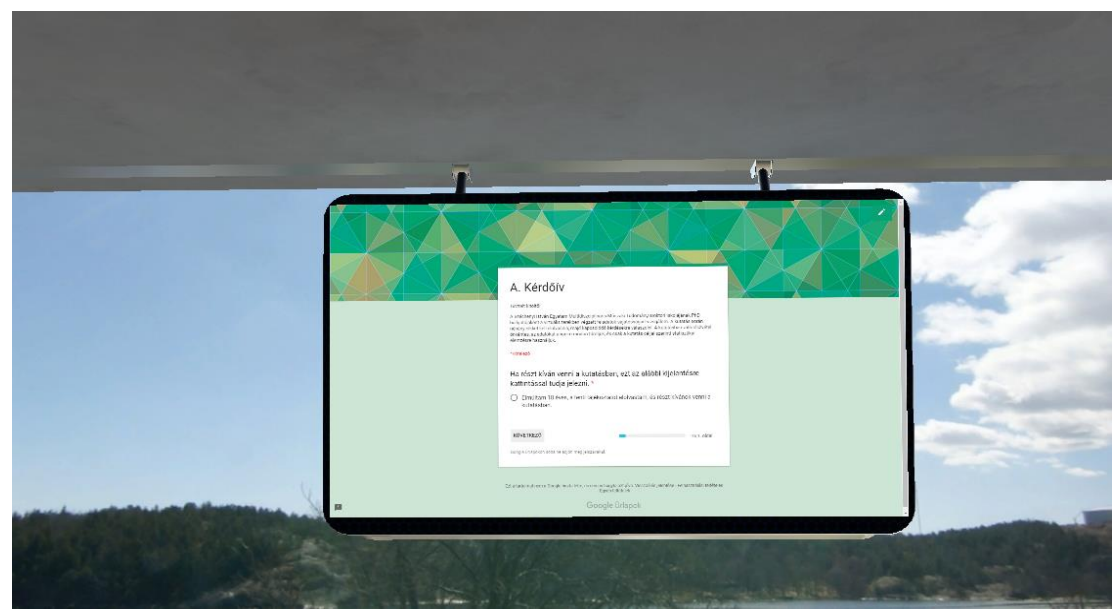

Figure 5

Online questionnaire inserted in the VR environment for all participants

\section{Results}

In the statistical analysis we included only the results of those participants who answered positively to the questions about the articles, therefore 22 individuals' results were analyzed, from the original 27 participants.

Our hypothesis was that those individuals will recall the advertisement, who have seen it in the VR space, and not in the articles. To compare the memory performance of the individuals in the two group we used the Fisher's Exact Test. The null hypothesis of the test was that the proportion of the remembering participants in the two group are equal. At the cut point of 0.05 , we want to test whether any observed difference of the proportions is significant. The results indicated a significant difference in the memory performance between the VR group with a prevalence of $91.67 \%$ (11/12), compared to $40 \%(4 / 10)$ in the classic web-based group $(\mathrm{p}=0.02)$. Which means that we can reject the null hypothesis, and assume that the proportion of the individuals who remember the advertisement is different in the two group.

The free recall test (Table 1) revealed that if an individual remembered the advertisement, then most of them could recall the promoted product and the brand. They also tried to recall the colors of the advertisement, but mostly they attributed the color of the brand to the color of the product. In this comparison, there was no statistically significant difference between the performance of the VR based and web-based group. 
Table 1

Results of the free recall and the corresponding p-value of the Fisher's Exact Test

\begin{tabular}{|c|c|c|c|}
\hline & VR & $\begin{array}{l}\text { Classic } \\
\text { web- } \\
\text { based } \\
\end{array}$ & $\begin{array}{c}\text { p-value of } \\
\text { Fisher's Exact } \\
\text { Test }\end{array}$ \\
\hline \multirow{6}{*}{$\begin{array}{l}\text { Ad } \\
\text { Product } \\
\text { Brand } \\
\text { Colors of } \\
\text { the ad } \\
\text { Color of } \\
\text { product } \\
\text { Slogan }\end{array}$} & $11 / 12$ & $4 / 10$ & 0,02 \\
\hline & $10 / 12$ & $4 / 4$ & 1 \\
\hline & $9 / 12$ & $3 / 4$ & 1 \\
\hline & $4 / 12$ & $0 / 4$ & 0.52 \\
\hline & $0 / 12$ & $0 / 4$ & 1 \\
\hline & $1 / 12$ & $0 / 4$ & 1 \\
\hline
\end{tabular}

\section{Discussion}

Our aim was to compare the classic web-based and VR based 2D advertisements, its effectiveness. According to our results, if a $2 \mathrm{D}$ advertisement is placed directly in a 3D virtual space, users are more likely to recall the advertisement and the advertised product, compared to an advertisement inserted in a website. If a participant could recall the advertisement, the results of the free recall test do not show any differences in the recall of its details. This can be the effect of the location of the ads. People tend to block and avoid ads in everyday life. Accordingly, they could learn not to pay attention to the banner ads, displayed on many different websites. However, in the VR advertisement, the ad is placed between the different contents and not inside them and participants did not use this avoiding behavior. To sum up, this different layout could increase the effectiveness of a 2D advertisement. The recall performance in the VR advertisement group resembles the billboard advertisements effectiveness in the experiment of Grigorovici and Constantin [31], where they found that billboard advertisements in a low arousing 3D virtual world are more effective than product placements.

Immersion and presence are key factors in the research of VR. The feeling of presence influences how ad format (2D or 3D) effects advertising effectiveness [27] and high presence increases the recall of advertisements [32]. In our experiment participants in both groups used the same VR environment, then the feeling of immersion and presence probably do not differ in the two groups. We did not measure the presence directly thus this limits our conclusions. The difference between the performance in the two group is not because of the novelty effect of the virtual space, or the feeling of the presence, but the different layout of the two advertisements. 
These results show, that advertisers do not have to design an own virtual space to create an experience with the product like in transformational marketing, but with the classic banner ad style advertisement, they can reach a more effective advertisement if they place it in a 3D virtual space instead of a classic website. Moreover, the media credibility which is a crucial question in online marketing [7], is already given, as the users already have chosen the software and all the contents are selected by themselves, presumably they evaluate as credible sites.

For further researches, we would like to use more Likert-scale questions, for example, to indicate the degree of the strength of the memory of advertisement or to indicate the level of irritation when they see these ads. Future research should investigate whether these effects appear in the case of animated, pop-up, and video ads too.

\section{Conclusions}

2D advertising in VR is more effective than in the classic banner ad format, our study confirms that ads in VR evoke better memory, namely more participants remembered the advertisement displayed in VR than in the web-based ad.

\section{Acknowledgement}

This work was supported by the FIEK program (Center for cooperation between higher education and the industries at the Széchenyi István University, GINOP2.3.4-15-2016-00003).

I would like to offer my special thanks to Prof. Dr. Péter Baranyi for his guidance and support. I wish to acknowledge the help provided by Dr. Ádám Csapó.

\section{References}

[1] Interactive Advertising Bureau, "IAB Internet Advertising Revenue Report," December 2017 [Online] Available: https://www.iab.com/wpcontent/uploads/2017/12/IAB-Internet-Ad-Revenue-Report-Half-Year-2017REPORT.pdf. [Accessed 02. 01. 2018.]

[2] L. Ha, „Online Advertising Research in Advertising Journals: A Review,” Journal of Current Issues \& Research in Advertising, pp. 31-48, 2008

[3] H. Li és J. L. Bukovac, „Cognitive Impact of Banner Ad Characteristics: An Experimental Study," Journalism \& Mass Communication Quarterly, pp. 341-353, 1999

[4] K. S. Burns és R. J. Lutz, „The Function of Format: Consumer Responses to Six On-line Advertising Formats," Journal of Advertising, pp. 53-63, 2006

[5] W. Flores, J.-C. V. Chen és W. H. Ross, „The Effect of Variations in Banner Ad, Type of Product, Website Context, and Language of Advertising on Internet Users' Attitudes," Computers in Human Behavior, pp. 37-47, 2014 
[6] S. M. Edwards, H. Li és J.-H. Lee, „Forced Exposure and Psychological Reactance: Antecedents and Consequences of the Perceived Intrusiveness of Pop-Up Ads," Journal of Advertising, pp. 83-95, 2002

[7] S. M. Choi és N. J. Rifon, „Antecedents and Consequences of Web Advertising Credibility: A Study of Consumer Response to Banner Ads," Journal of Interactive Advertising, pp. 12-24, 2002

[8] S. Rodgers és E. Thorston, „The Interactive Advertising Model: How users Perceive and Process Online Ads," Journal of Interactive Advertising, pp. 4160,2000

[9] L. Ha, „Advertising Clutter in Consumer Magazines: Dimensions and Effects," Journal of Advertising Research, pp. 76-85, 1996

[10] J. W. Brehm, A Theory of Psychological Reactance, Oxford, England: Academic Press, 1966

[11] P. G. Lindmark, „A Content Analysis of Advertising in Popular Video Games," ETD Archive, 2011

[12] I. Horváth, „Innovative Engineering Education in the Cooperative VR Environment," in $7^{\text {th }}$ IEEE International Conference on Cognitive Infocommunications (CogInfoCom), Wroclaw, 2016

[13] I. Horváth, Teaching Disruptive Technologies in a Virtual Educational Environment Using the Edu-Coaching Method (Ph.D. Dissertation) 2017

[14] I. Horváth, „Disruptive technologies in higher education,” in th IEEE International Conference on Cognitive Infocommunications (CogInfoCom) Wroclaw, 2016

[15] G. Csapó, „Sprego virtual collaboration space,” in $8^{\text {th }}$ IEEE International Conference on Cognitive Infocommunications (CogInfoCom) Debrecen, 2017

[16] G. Csapó, „Sprego virtual collaboration space: Improvement guidelines for the MaxWhere Seminar system," in $8^{\text {th }}$ IEEE International Conference on Cognitive Infocommunications (CogInfoCom) Debrecen, 2017

[17] K. Biró, G. Molnár, D. Pap és Z. Szüts, „The effects of virtual and augmented learning environments on the learning process in secondary school," in $8^{\text {th }}$ IEEE International Conference on Cognitive Infocommunications (CogInfoCom) Debrecen, 2017

[18] I. Horváth, „The IT device demand of the edu-coaching method in the higher education of engineering," in $8^{\text {th }}$ IEEE International Conference on Cognitive Infocommunications (CogInfoCom) Debrecen, 2017 
[19] Z. Kvasznicza, „Teaching electrical machines in a 3D virtual space,” in $8^{\text {th }}$ IEEE International Conference on Cognitive Infocommunications (CogInfoCom) Debrecen, 2017

[20] G. Bujdosó, O. C. Novac és T. Szimkovics, „Developing cognitive processes for improving inventive thinking in system development using a collaborative virtual reality system," in $8^{\text {th }}$ IEEE International Conference on Cognitive Infocommunications (CogInfoCom) Debrecen, 2017

[21] A. Gilányi, G. Bujdosó és M. Bálint, „Presentation of a medieval church in MaxWhere," in $8^{\text {th }}$ IEEE International Conference on Cognitive Infocommunications (CogInfoCom) Debrecen, 2017

[22] W. W. Kassaye, „Virtual Reality as Source of Advertising,” Journal of Website Promotion, pp. 103-124, 2007

[23] T. Griffin, J. Giberson, S. H. M. Lee, D. Guttentag, M. Kandaurova, K. Sergueeva és F. Dimanche, „Virtual Reality and Implications for Destination Marketing," in Tourism Travel and Research Association: Advancing Tourism Research Globally, 2017

[24] S.-A. A. Jin és J. Bolebruch, „Avatar-Based Advertising in Second Life: the Role of Presence and Attractiveness of Virtual Spokesperson," Journal of Interactive Advertising, pp. 51-60, 2009

[25] H. Tikkanen, J. Hietanen, T. Henttonen és J. Rokka, „Exploring Virtual Worlds: Success Factors in Virtual World Marketing," Management Decision, pp. 1357-1381, 2009

[26] Y. K. Choi és C. R. Taylor, „How Do 3-dimensional Images Promote Products on the Internet?," Journal of Business Research, pp. 2164-2170, 2014

[27] S. Debbabi, M. Daassi és S. Baile, „Effects of Online 3D Advertising on Consumer Responses: the Mediating Role of Telepresence," Journal of Marketing Management, pp. 967-992, 2010

[28] H. Li, T. Daugherty és F. Biocca, „Impact of 3-D Advertising on Product Knowledge, Brand Attitude, and Purchase Intention: The Mediating Role of Presence," Journal of Advertising, pp. 43-57, 2002

[29] H. Van Kerrebroeck, M. Brengman és K. Willems, „When Brands Come to Life: Experimental Research on the Vividness Effect of Virtual Reality in Transformational Marketing Communications," Virtual Reality, pp. 177-191, 2017 
[30] R. B. Zajonc, „Attitudinal Effects of Mere Exposure,” Journal of Personality and Social Psychology, pp. 1-27, 1968

[31] D. M. Grigorovici és C. D. Constantin, „Experiencing Interactive Advertising Beyond Rich Media," Journal of Interactive Advertising, pp. 22-36, 2004

[32] C.-J. Keng és H.-Y. Lin, „Impact of Telepresence Levels on Internet Advertising Effects," CyberPsychology \& Behavior, pp. 82-94, 2006

[33] E. Z. Borba és M. K. Zuffo, „Advertising Perception with Immersive Virtual Reality Devices," in IEEE Virtual Reality (VR) 2017

[34] "http://www.maxwhere.com/" [Online] [Accessed 11 October 2017] 